Pakistan Journal of Education

Vol.38, No.2, 2021, 77-89

\title{
Helping Students to Get Better Grades in Mathematics at the Elementary Level
}

\author{
Naheed Khurshid* \\ Hafiz Muhammad Ather khan** \\ Hafiz Shehzad Ali ${ }^{* * * *}$
}

\begin{abstract}
The current study is conducted to explore the learning potential of students at the elementary level by using the scaffolding technique. The study aimed to measure the efficiency of the scaffolding teaching method provided to the students at the elementary level. The sample was selected from Gov. Girls Higher Secondary School Model Town A, Bahawalpur, Punjab, Pakistan. All 6th classes of this school were included in the sample. Retention of learning after 3 months, the provision of scaffolding in comparison to the traditional method was assessed. Solomon's fourgroup design was used for this experiment in which there were 40 students in each group and 160 in total. One-sample t-test was used to analyze the data using SPSS version 20.0. The Data revealed that scaffolding was proved to be a better strategy as traditional teaching methods as compared to the control group. Study recommended that scaffolding teaching needs a highly structured supervised environment and may be conducted in controlled conditions. Furthermore, the prospective teachers may be prepared in the principles, procedures, and rules of scaffolding.
\end{abstract}

Keywords: scaffolding, ZPD, intervention, retention

PhD Scholar, Department of Education, The Islamia University of Bahawalpur, Bahawalpur, Pakistan. Email: naheedbwp@gmail.com

** Department of Educational Training, The Islamia University of Bahawalpur, Bahawalpur, Pakistan. Email: Muhammad.ather@iub.edu.pk

*** Department of media Studies, The Islamia University of Bahawalpur, Bahawalpur, Pakistan. Email: shehzadali778@gmail.com 


\section{Introduction}

Math subject plays a crucial part in contemporary society because of its importance and consumption. The swift development in science has grown mathematical study and led to further wide-ranging usage of this subject in routine and Information \& technology. The said developments claim more improvement and up gradation in the curriculum of this subject. Mathematics keeps supreme place in the school curriculum due to its indispensable consideration for educated people. In the Elementary schools, Mathematical information contains greatest computational arithmetic measurements that's a crucial function in societal education, and now it is thought to be the most useful way of education than before.

Mathematics keeps supreme importance at elementary level of education. The students with excellent mathematical comprehension are more likely to perform extraordinary in their prospective education and job performance (Salkin, 2008).

The students without conceptual comprehension of mathematics are seemed to be disadvantaged of efficiency in classrooms and in their routine activities. Because of the global usefulness of mathematics, this subject has more importance (Charles-Ogan, 2019). Some students are observed getting secondary and higher education after getting elementary education. Most of the students, after elementary education, in developing and underdeveloped states, can't continue education. They leave the school education and keep start earning (Boaler, 2016).

Moreover, scaffolding can be seen as limited support and reinforcement for the students given by their teachers or their peer students. Teachers and peer students can scaffold only if they have better learning experiences, knowledge, understanding, comprehension of mathematical concepts than the other students. The purpose of this limited support is to enable the student's independent learners to construct their own knowledge for the solution of mathematical problems. The limited support involves explanation, indication, inspiration, and frameworks or sketches for the solution of problems. This support enables the students to access the level of autonomous learning (Tropper, 2015; Wood, 2003).

Mathematics is important in both cases for all learners. For those who leave the study and do job, market give importance to those having more mathematical understanding. Hence, all must have comprehensive performance at elementary level of education. Study has shown that all individuals do not show satisfactory results in mathematical understanding in developing and underdeveloped countries at elementary level. Apart from many other related factors, there is another reason of failure in mathematics is the poor instructional method of (Ezeh \& Ugwuanyi, 2013). 
In scaffolding process of mathematics, modeling strategy also involves the verbalization of students' mathematical ideas with their peer students and teachers, However, in a classroom with collaborative scaffolding settings, teachers use the modeling in strategy two ways. Teachers share their thinking about content of mathematics and the process of communication and cooperative learning with their students. When the teachers apply collaborative teaching strategy as an intervention, they may face some challenges. These challenges may be in the form of classroom control, preparation of lesson according to collaborative settings, students with individual learning abilities, and teachers own responsibilities for learning of individual student (Brush \& Saye, 2000; Kajamies et al., 2010).

Classroom work, homework and educator's instructions are the important tools to understand mathematics for the students through which they are busy for solving questions. The instructions given by the teachers to understand mathematical learning help the students for concentrating the required skills to solve math questions (Ball \& Bass, 2003; Sunday et al., 2014).

The instructions provided by the teacher for mathematics are the beneficial content for the classroom. Such method of teaching give chance for students to actively join classroom actions and solve mathematical difficulties more effectively. It reduces the anxiety and misunderstanding of students related to mathematics subject. With traditional way of mathematical teaching, students do not find enough chances for sharing their mathematical thoughts with other peer students and teachers as well (Remalyn, 2013; reingold, 2008).

The students face difficulties to understand mathematics due to the misconception with the fundamental ideas of this subject. Scaffolding provides more related support to solve the problems of the students to resolve mathematical problems and activities in classroom as (Jumaat et al, 2014; Obioma, 2011). Scaffolding technique is the process of teaching in which teacher guides the learners. In the developed countries, number of researches show that scaffolding teaching method shows better results in students' understanding (Clare, 2012; Diwantoro, 2010; Helton \& Clark, 2006).

The researchers and educators of mathematical subject has found that the successful strategies to teach the students are those which help them within the zone of proximal development of students (Smagorinsky, 2007; Tan, 2013; Vygotsky, 1978). Such method of teaching is more effective in developing and underdeveloped countries. It has been found that in Pakistan, a developing country, centered method of teaching is used for teaching mathematical subject. This said reason has obliged the researcher to conduct current study for measuring scaffolding results in students' progress in mathematics. 
Scaffolding is a fundamental assistance or sequence of techniques what're implemented while learning process for bringing maximum attainment, understanding and yield that chiefly focusses for getting educational objectives. It is basically a impermanent, arranged and progressive support given by the teachers to the students for getting maximum level of knowledge and assists in skills gaining that's not possible for them to promote them by their own without said support (Anghileri, 2006; Azevedo \& Hadwin, 2005). Scaffolding is seen as impermanent, planned or responsive help that supports the learners for moving towards the newest techniques, concepts, or steps of comprehension (Elbers, 2013; Estany \& Mortinez, 2014).

Hence, majority of definitions are seeming alike features depending upon the contextual concept. There are three fundamental features of scaffolding wherein the first; the teachers familiarize their assistance to the students as an illustrational diagnostic strategy. In the second feature of scaffolding, there is a gradual teacher's withdrawal support that's known as fading. The third feature of scaffolding is the responsibility shift from teachers to students. This kind of said shifting responsibility form the student's free and independent learners (Gibbons, 2002; Gonzalez \& Dejarnette, 2015).

Without knowing the significance of language for the reasoning of mathematics, a teacher can't be conscious of linguistic supporter to the second-language learner in context to mathematics. Moreover, the intentional aspect is important link among handover and responsiveness. The responsive actions are done for helping students to do their tasks independently or corresponding to their responsibilities (Visnovska \& Cobb, 2015).

Retrospectively, the region is seemed to be the instrumental variety of Vygotsky's Zone of Proximal Development (ZPD). He defined it as a distance among actual developmental level of a child depicted by independent issue solving, and potential development highlighted by their capabilities for solving the problem with the adults (Vygotsky, 1978).

Research has been shown that scaffolding may assist students to increase their metacognition, therefore, it makes easier for relating the content for the students (Holton \& Clarke, 2006). Such thoughtful understanding may assist the students developing cognitive constructions which help both the metacognition and self-efficacy. The flexible and movable scaffolding is required for creating individual creativity for having more autonomous and free learners (Pfister, 2015).

The scaffolding techniques in learning activities may be designed for learning procedure via arrangements and presentations of contents as delineated in worksheets or study guides that would be provided to 
students. Such techniques may also be utilized while learning procedure when teachers manage learning activities for engaging the students vigorously to construct and understand the content. The teachers are recommended for recognizing or figuring out the mathematical reasoning of students, judging how the student's ideas keep potential for contributing to mathematical objectives as of discussion, knowing or figuring out if or how the ideas of students keep relevancy to the development of their understanding regarding math subject (Smit et al., 2013).

The collaborative learning in mutual groups are seen by making small groups and, via such groups, the students work collectively for ensuring that every student takes a part sufficiently in the activities or mutual duties. To become a fruitful learner, the effective communication and collaborative efforts are very crucial. Fundamentally, it is applicable via communication and by investigating various point of views through which the students gain informative strategies, self-determination and empathy. Further this kind of learning strategies are the portion of John Dewey's social studies project, that's enormously subsidized to improve the learning generally. Now, it's become a true alternative for traditional strategies due to its substantial character to improve academic performance and the aspects of social learning (Pederson, 2003; Reiser, 2004).

The worldwide usage of collaborative learning strategies has been implemented since early 20th century. These strategies are considered to be the most crucial techniques in the field of teaching. Such teaching methods enhance cooperation and connection among students and eliminates the bad habits of competitive perception among them. Additionally, the students are involved in real world errands and link new comprehensions to boost their knowledge, demand appropriate communication and support between tutors, learners and others. It is obvious that through communication and interaction, the curriculum goals remain alive (Pea, 2004).

The teachers play their influential part to ease the students in the process of effective learning. Though, the role of tutors is usually mentioned briefly and seemed to be like facilitator which comprises making an ironic atmosphere and actions for connecting new info to prior information, delivering occasions for collaborative efforts and problemsolving tools and, as providing the students comprehensive learning activities. Further, the teacher uses modeling: as it's been highlighted by various local and state rules as transferring someone's perception and representing or interpreting anything (Brinkerhoff \& Glazewski, 2004).

Although, modeling in the collaborative classrooms supports students not only sharing someone's perception about the material to learned, but also the procedure of dialogue and mutual learning. Modeling 
can be involved in the narrative of student's perception with their tutors and the peer students. The one more function of the teachers is to advise the students from early school time to assess their learning period. When teachers shift their medium from conventional method to collaborative means of instructions, various crucial challenges may appear containing; classrooms control, groundwork time for such learning atmosphere, one by one dissimilarities among the students, and distinct responsibilities of teaching (Makar., 2015).

Corresponding to the scaffolding process, the reviewing and restructuring involves straight interaction among teachers and students relate to the subject of mathematics in prior. The groups of reviewing and restructuring recognize the patterns of interaction that are more productive to learners and, the intended groups widens the focusing ideas. It's observed that showing and communicating have seen traditional in the classroom education for peers and remain continuing in the classroom domains. By applying such strategies, teachers retain control and conduct structured communication for taking account of further step which they've thought with the little use of student's efforts (Esquinca, 2011).

\section{Objectives of Study}

1. To analyze the impact of scaffolding on retention of mastery over given concepts of mathematics at the elementary level.

2. To explore new developmental span of students learning outcomes through scaffolding.

\section{Research Methodology}

The current study was experimental and quantitative. There were two experimental and two control groups in the study. All groups from class 6th, two are taken based on pretest score. Solomon's four-group design was used in this research. This design was used to measure the effectiveness of treatment involving two groups. It includes pretest, posttest and retention test as research tool. There were 160 total participants in this study containing 40 students in each group, who were studying in Grade $6^{\text {th }}$ taken as a sample from Govt. Girls Higher Secondary Bahawalpur. The groups formed from four intact classes with the approximately same characteristics such as age, academic position, social background, and abilities. 


\section{Data Analysis and Results}

Table 1

Academic performance of experimental and control groups

\begin{tabular}{lcccc}
\hline & One-Sample Statistics & & \\
\hline Tests & $\mathrm{N}$ & Mean & Std. Deviation & Std. Error Mean \\
Experimental Group & 40 & 19.1125 & 17.51269 & 1.13044 \\
Post- test _Pre -test & 40 & -1.2542 & 2.66819 & .17223 \\
Retention- test- Post-test & 40 & 17.2208 & 16.15087 & 1.04253 \\
$\quad$ Control Group & 40 & -11.9750 & 11.54976 & .74553 \\
$\quad$ Post-test -_Pre-test & 40 & -2.2083 & 3.61285 & .23321 \\
Ret test -_Post-test & & & & .67927 \\
$\quad$ Experimental Group 2 & 40 & -10.0000 & 10.52314 &. \\
$\quad$ Retention- test - Post-test & & & & \\
$\quad$ Control Group 2 & & &
\end{tabular}

The above table number 1 shows the numerical values from the selected samples. All above-mentioned tests contain equally 40 participants wherein, the mean value of experimental posttest and experimental pretest is 19.1125 and standard deviation as up to 17.51269 . The mean value of the experimental retention test and experimental posttest is -1.2542 while the standard deviation has been 2.66819. In addition to the control posttest and control pretest, the mean value has been 17.2208 and the standard deviation as 16.15087. Further, the control retention and control posttest contain a mean value of -11.9750 and a standard deviation of 11.54976. The next experimental 2 retention test and experimental 2 posttest contains a mean value of -2.2083 and standard deviation up to 3.61285. The control group 2 retention test and control 2 post have a mean value of -10.0000 and standard deviation of 10.52314 .

Table 2

Frequency of testing groups

\begin{tabular}{lcccc}
\hline & $\begin{array}{c}\text { One-Sample t-Test } \\
\text { Test Value = 0 }\end{array}$ & & \\
\hline Tests & T & DF & Sig. (2-tailed) & $\begin{array}{c}\text { Mean } \\
\text { Difference } \\
\text { Experimental Group }\end{array}$ \\
$\begin{array}{l}\text { Post-test - Pre-test } \\
\text { Experimental Group }\end{array}$ & 16.907 & 39 & .000 & 19.11250 \\
$\begin{array}{l}\text { Retention-test - post-test } \\
\text { Control Group }\end{array}$ & -7.282 & 39 & .000 & -1.25417 \\
$\begin{array}{l}\text { Post-test - Pre-test } \\
\text { Retention-test - Post-test }\end{array}$ & 16.518 & 39 & .000 & 17.22083 \\
Experimental Group 2 & -16.062 & 39 & .000 & -11.97500 \\
Retention-test - Post-test & -9.469 & 39 & .000 & -2.20833 \\
Control Group 2 & -14.722 & 39 & .000 & -10.00000 \\
Retention-test - Post-test & & & & \\
\hline
\end{tabular}


The above table interprets the $\mathrm{T}$ value, degree of freedom, and the mean difference from the concerning tests. The $\mathrm{T}$ value of Experimental post-test and experimental pre-test has 16.907, experimental retention and experimental post-test have -7.282, the control post and control pretest have 16.518, the control retention and control posttest have -16.062 , the experimental retention and experimental posttest have t-value -9.469 and, the control Group 2 retention t-value is -14.722 i.e. applied on retention score - post-test score means. The degree of freedom was 39. As mean differences were, the experimental posttest and experimental pretest was 19.11250, experimental retention and experimental posttest have 1.25417, control post-test and control post-test and control pre-test have 17.22083, control retention and control posttest have difference of 11.97500, experimental 2 retention and experimental 2 post-test having 2.20833 while, the control 2 retention and control 2 post-test have difference of -10.00000 as a mean difference.

\section{Conclusions}

The study concluded that students' pre-test scores revealed both experimental and control group as equivalent, post-test showed that performance of experimental group participants' is better than that of students of control group. Secondly, results of post-test showed that participants of the experimental group got more scores than control group students in context to understanding, remembering, ability to write questions, process solving, writing answers (rubrics of tests). Moreover, it is found that the academic achievement and performance, the comparative progress of experimental groups is greater than control groups. The study also concluded that academic scaffolding in teaching methodologies proved to be useful than traditional methods. From the comparative findings of both experimental groups and control groups, it is found that by scaffolding teaching method, the students' performance under the zone of proximal development can be enhanced. Further, it is averred that the retention of knowledge of experimental groups were higher than control groups. It is also concluded that teaching by the provision of scaffolding helps in retaining the knowledge for a long period with finer understanding and with greater learning potentials. The researchers also found that the motivation level of students during intervention was higher than traditional classes. 


\section{Recommendations}

On the basis of the findings of the study and conclusion, the following recommendations were made.

- There should be a scaffolding center in each school at the elementary level for the different subjects to help low achievers for enhancing their zone of proximal development.

- Scaffolding teaching needs a highly structured supervised environment and may be conducted in controlled conditions. It is recommended that in teacher education, the prospective teachers may be prepared in the principles, procedures, and rules of scaffoldings.

- There is an urgent need that teachers to be trained according to the provision of scaffolding for long-term learning and retention of knowledge in difficult subjects. 


\section{References}

Anghileri, J. (2006). Scaffolding practices that enhance mathematics learning. Journal of Mathematics Teacher Education, 9, 33-52.

Azevedo, R., \& Hadwin, A. F. (2005). Scaffolding self-regulated learning and metacognition-Implications for the design of computer-based scaffolds. Instructional Science, 33, 367-379.

Ball, D. L., \& Bass, H. (2003). Toward a practice-based theory of mathematical knowledge for teaching. In B. Davis \& E. Simmt (Eds.), Proceedings of the 2002 annual meeting of the Canadian Mathematics Education Study Group (pp. 3-14). CMESG/GDEDM.

Boaler, J. (2016). Mathematical mindset: Unleashing students potential through creative math, inspiring messages and innovative teaching. Jossey-Bass

Brinkerhoff, J. \& Glazewski, K. (2004). Support of expert and novice teachers within a technology enhanced problem-based learning unit: A case study. International Journal of Learning Technology 1, 219-230.

Brush, T. \& Saye, J. (2000). Design, implementation, and evaluation of student centered learning: A case study. Educational Technology Research and Development 48(2), 79-100.

Charles-Ogan, G. (2019). Mathematics as a tool for achieving the vision 20:2020 goal of national transformation. International Journal of Education, Learning and Development.3(8), 57-61.

Clare, V. B. (2012). Scaffolding Students Opportunities to Learn Mathematics through Social Interactions. Mathematics Education Research Group of Australasia. Publishes online August 23, 2012.

Diwantoro, H. (2010). The Use of Scaffolding Approach to Enhance Students' Engagement in Learning Structural Analysis. Journal of International Education Studies. 3(1),135-140.

Esquinca, A. (2011). Bilingual college writers' collaborative writing of word problems. Linguistics and Education, 22(2), 150-167. 
Ezeh, S. I. \& Ugwuanyi, C. C. (2013). Transformation of mathematics education programme. A step towards the attainment of vision 20:2020 Abacus. Journal of Mathematical Association of Nigeria, $38(1), 75-82 /$

Gibbons, P. (2002). Scaffolding language, scaffolding learning: Teaching second language learners in the mainstream classroom. Heinemann.

Gonzalez, G., \& DeJarnette, A. F. (2015). Teachers' and students' negotiation move when teachers scaffold group work. Cognition and Instruction, 33(1), 1-45.

Holton, D. \& Clarke, D. (2006). Scaffolding and metacognition. International Journal of Mathematical Education on Science and Technology, 37(1), 127-143.

Jumaat, Nural, Farhana \& Zaidation, T. (2014). Instructional Scaffolding in online Learning Environment: Meta-analysis. Presented at the 2014 International Conference on Teaching and Learning in Computing and Engineering

Kajamies, A., Vauras, M., \& Kinnunen, R. (2010). Instructing low achievers in mathematical word problem solving. Scandinavian Journal of Educational Research, 54(4), 335-355.

Makar, K., Bakker, A., \& Ben-Zvi, D. (2015). Scaffolding norms of argumentation-based inquiry in a primary mathematics classroom. ZDM Mathematics Education, 47(7), 37-46.

Obioma, U. A. (2011). Re-Branding the Strategies for Teaching Mathematics: The Case of Scaffolding. Proceeding of September 2011 Annual NationalConference.1-7.and Attitudes. Comprehensive Journal of Educational Research. 10, 9-19.

Pea, R. D. (2004). The social and technological dimensions of scaffolding and related theoretical concepts for learning, education, and human activity. Journal of the Learning Sciences, 13(3), 423-451.

Pederson, S. (2003). Motivational orientation in a problem-based learning environment. Journal of Interactive Learning Research, 14, 51-77.

Pfister, M., Moser Opitz, E., \& Pauli, C. (2015). Scaffolding for mathematics teaching in inclusive primary classrooms: A video study. ZDM Mathematics Education, 47(7), 56-68. 
Reingold R. (2008). Instructors scaffolding in support of student's metacognition through a teacher education online course: a case study Journal of Interactiveonline Learning, 7(2),139-151, 2008.

Reiser, B. J. (2004). Scaffolding complex learning: The mechanisms of structuring and problematizing student work. The Journal of the Learning Sciences, 13, 273-304.

Remalyn, Q. C (2013). Scaffolding Strategy is Teaching Mathematics its Effect on Students Performance

Salkin, N. J. (2008). Encyclopedia of educational psychology. SAGE publication.

Saye, J. W. \& Brush, T. (2002). Scaffolding critical reasoning about history and social issues in multimedia-supported learning environments. Educational Technology Research and Development, 50(3), 77-96.

Smagorinsky, P. (2007). Vygotsky and the social dynamic of classrooms. English Journal, 97(2), 61-66.

Smit, J., \& VanEerde, H. A. A. (2013). What counts as evidence for the long-term conversation of whole-class scaffolding? Learning, Culture and Social Interaction, 2(1), 22-31.

Suleman Q., \& Gul, R. (2015) Factors Affecting Quality of Primary Education in Kohat Division, Pakistan. Research on Humanities and Social Sciences, 5(7), 64-77.

Sunday, Y., Akamu. M. A. \& Fajemidagba, M. O. (2014). Effects of Target-Task Mode of teaching on Students' Performance in Geometrical Construction. Abacus. Journal of Mathematical Association of Nigeria, 39(1),33-42.

Tropper, N., Leiss, D., \& Hanze, M. (2015). Teachers' temporary support and worked-out examples as elements of scaffolding in mathematical modeling. ZDM Mathematics Education, 47(7), 13-27.

Visnovska, J., \& Cobb, P. (2015). Learning about whole-class scaffolding from a teacher professional development study. ZDM Mathematics Education, 47(7), 24-37.

Vygotsky, L. S. (1978). Mind in society: The development of higher psychological processes. Harvard University Press. 
Wood, D. (2003). The why? What? When? and how? of tutoring: The development of helping and tutoring skills in children. Literacy Teaching and Learning, 7(2), 1-30.

Citation of this Article:

Khurshid, N., Khan, H. M. A., \& Ali, H. S. (2021). Helping students to get better grades in mathematics at the elementary level. Pakistan Journal of Education, 38(2), 77-89. 
